\title{
The relationship between the graduate trainee programme and talent management in corporate organisations in Eswatini
}

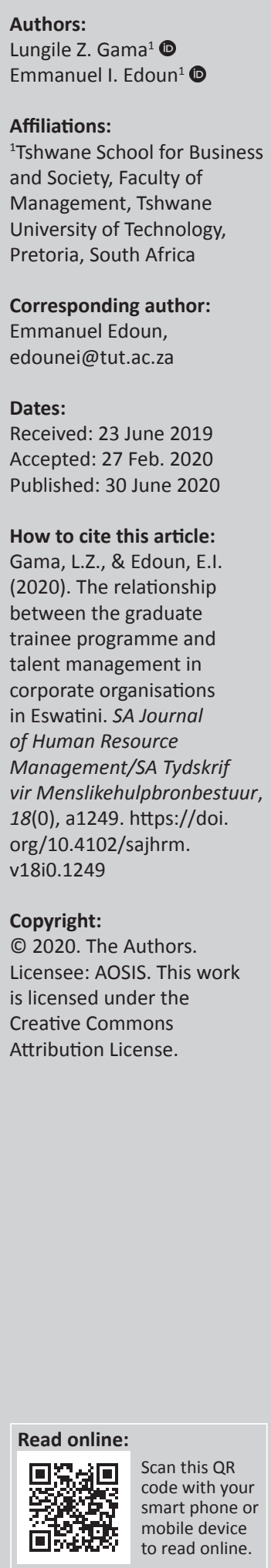

Orientation: Research on the existence of the relationship between the GTPs and TM has been necessitated by the significant organisational resources invested in the administration of GTPs. Withal, the valueof GTPs to an organisation's TM initiatives needs to be ascertained because both variables are applied to ensurethat future staffing requirements are met.

Research purpose: The aim of this study was to assess the relationship between the graduate trainee program (GTP) and talent management (TM) in corporate organisations in Eswatini.

Motivation for the study: Corporates need toexplore administering GTPs as structured processes such as workplace training and development programs so that they significantly contribute to TM.

Research approach/design and method: A quantitative explanatory design was applied to carry out the study.The population was five corporate organisations in Eswatini that administer GTPs. The respondents weregraduate trainees (GTs), who met all the requirements prescribed by the inclusion criteria.

Main findings: While the results indicated a null hypothesis in the relationship between GTPs and TM a strong correlation was found. The conclusion drawn is that the strong correlation ( $r=0.511)$, between GTPs and TM, is attributed to the lack of integration and the parallel and independent administration of GTPs to TM, which invalidated a link between the two variables.

Practical/managerial implications: The value to be derived by corporates administering GTPs may be elusive if the relationship between GTPs and TM remains unexplored.

Contribution/value-add: Corporate organisationswill administer GTPs as effective management tools applied to ensure TM.

Keywords: graduate trainee programmes; talent management; workplace training; development programmes; strategies.

\section{Introduction}

Great leaders attend to people first and strategy second, get the right people in the bus, move the wrong people off, usher the right people to the right seats and figure out where to drive it. (Collins, 2011, p. 124)

In an effort to get the right talent into the organisation at inception, corporate organisations in Eswatini are administering graduate trainee programmes (GTPs) as a long-term strategy to identify the leadership and managerial potential of graduates, so that the latter can be groomed accordingly to assume critical, managerial and leadership roles in the organisation. Graduates are sourced through strategic partnerships that organisations form with tertiary institutions (Mkhonta, 2010). The selection and recruitment of graduates are conducted solely on the basis of merit, which is evaluated through the performance of the individual in executing key objectives of the GTPs.

Organisations put emphasis on merit as a basis for hiring newly qualified graduates. This can be attributed to the fact that individuals with a strong accountability of their careers, who are responsible and reliable, highly intelligent and success-driven, have the ability to learn more (Robins \& Judge, 2013, p. 588). As organisations attempt to cultivate their own calibre of employees 
through training and development to ensure the right fit between the people and the vision, merit should therefore be a strong factor in recruiting graduate trainees (Kotter \& Collins, 2011, p. 3). This can additionally ensure that recruited graduates are competent to receive the offerings of the GTPs. Merit is inevitably a highly determinant factor in hiring graduate trainees because the skills of talented employees and how they are organised are progressively perceived as key to an organisation's long-term success and competitive edge (Boudreau \& Ramstad, 2007, p. 4).

Talent management is primarily concerned with ensuring the adequate supply of talent to align the right people with the right skills, knowledge and experience at the right time based on strategic business objectives (Nel et al., 2011, p. 163). Patently the right fit between an organisation and the employee is the fundamental basis on which TM exists. Withal, if corporate organisations aim to utilise the GTPs as a strategy for ensuring TM, it is key that the GTPs are administered effectively, in consideration of the financial, time and intellectual resources invested by organisations in administering GTPs (Mkhonta, 2010).

Research pertaining to GTPs, albeit limited, does exist. Employers tend to follow a similar approach when engaging newly qualified graduates into a structured programme. Focus is on graduate identification and selection, workplace development, formal in-service training initiatives, apparent organisational relations with tertiary institutions, key organisational expertise and proficiencies required from graduates within the organisation as well as relational and reporting skills (Andrews \& Higson, 2010, pp. 411-422). Therefore, a balanced approach to the administration of GTPs would be integral in the value of the GTP to the graduate trainee.

\section{Literature review}

The link that was determined as a tie between the GTPs and talent management programmes (TMPs) was that both variables were utilised by organisations as long-term strategies aimed at ensuring that future staffing requirements were met. Graduate trainee programmes were applied as future staffing strategies through administering structured workplace training and development for newly qualified graduates entering the workplace, to ensure that applied training yielded the desired employee expertise in the newly qualified graduates, which would ultimately ensure that the desired organisational change was realised (Dirani, 2012, p. 5). Talent management was, in turn, applied to ensure that future staffing requirements were met through the methodical recruitment, selection, training, identification, appointment, motivation, retaining and stationing of talented employees who were of a particular value to an organisation to create a long-term competitive edge (Thunnusen et al., 2017, p. 3). The GTPs could therefore be utilised as significant contributors to TM, particularly because the Resource-Based View (RBV) on TM had as its main component, talented employees as the basis for key lasting competitive edge and the primary tenet for the future success of organisations and the RBV approach was one of the key pre-potent concepts in TM literature (Thunnusen et al., 2017, p. 92). Focusing on people as soon as they entered the organisation through utilising strategies such as GTPs could therefore enrich the RBV on TM.

Lawler (2017, p. 117) further acceded that TM was primarily centred on five main components: attracting, selecting, developing, rewarding and integrating TMPs to the overall organisational processes to have the required talented employees in the relevant positions at any given time. Dirani (2012) and Duplessis (2011, p. 7), in turn, summarily conceded that GTPs were also primarily centred on attracting, selecting, developing, rewarding and integrating GTPs into organisational process to ensure that organisations had the relevant human resources at the required time, with the relevant expertise and proficiencies that would ensure the future success of the organisation.

In addition, Waheed and Zaim (2015, p. 1206) argued that the need for attracting competent employees was one that was urgent for organisations. The GTPs could undeniably contribute to TM because they could be utilised as a tool for organisations to appraise well-performing graduate trainees who were eligible to proceed to permanent employment because they had met the required performance levels and possessed the relevant qualifications required by the organisation. Henceforth, organisations would be in a position to be able to establish a talent pool consisting of employees who were outstanding performers. Establishing a talent pool would inevitably enable an organisation to choose suitable employees from the established talent pool when the need to make placements to fill existing vacant positions arose. The establishment of a talent pool would, in turn, ensure that talented employees were placed in positions where they could be effective and advance the organisation, thus ensuring that both TM and career planning were accomplished.

The tenets that validate the link between GTPs and TMPs are summarised as follows. (see Figure 1).

If extensively explored, the tenets validating the link between the GTPs and TM could enable organisations to administer both programmes in an integrated manner to facilitate the application of GTPs as contributors to TM. The articulation of the link between GTPs and TM was supposed to be validated by the narrative that both variables were key leadership strategies applied to attract, select and develop organisational talent. Fostering valid TM through integrating workplace training and development programmes (WTDPs) such as GTPs could significantly maximise the benefits of administering both programmes in the organisations. Henceforth, the onus would be on corporate organisations in Eswatini to marry the two variables, based on the existence of the supposed link. De-parallelising the administration of both variables would ensure that corporate organisations derived value and benefitted extensively from the administration of the GTPs as contributors of TM. 


\section{Objectives}

The primary objective of this study was to assess the existence of a link between GTPs and TM through a comprehensive analysis of the impressions, understanding and perspectives of graduate trainees undergoing the programme within an Eswatini corporate environment context. This study explored the graduate trainees' unique perspective on the GTP models in so far as their contributors to TM.

\section{Research design}

A quantitative explanatory design was applied in carrying out the research study as it aimed to establish the possible causal relationship between variables (Saunders et al., 2016, p. 176). The researcher merged self and individually completed questionnaires and/or computerised questionnaires (De Vos et al., 2011, p. 188). The format of the questionnaire was designed in line with a Likert scale so respondents could rate their responses on a scale of 1-7, with 1 being strongly agree and 7 being strongly disagree. The researcher was guided by the preferences of the respondents insofar as computerised or physical completion of questionnaires. Collected data were immediately captured in an Excel spreadsheet to summarise and document the respondents' responses, for information security, for ease of analysis and for simplifying coding and tabulation. Participation in this study was strictly voluntary and this was communicated to all respondents before completing the questionnaire. De Vos et al. (2011, p. 117) advocate that participants should not be compelled to be involved in a

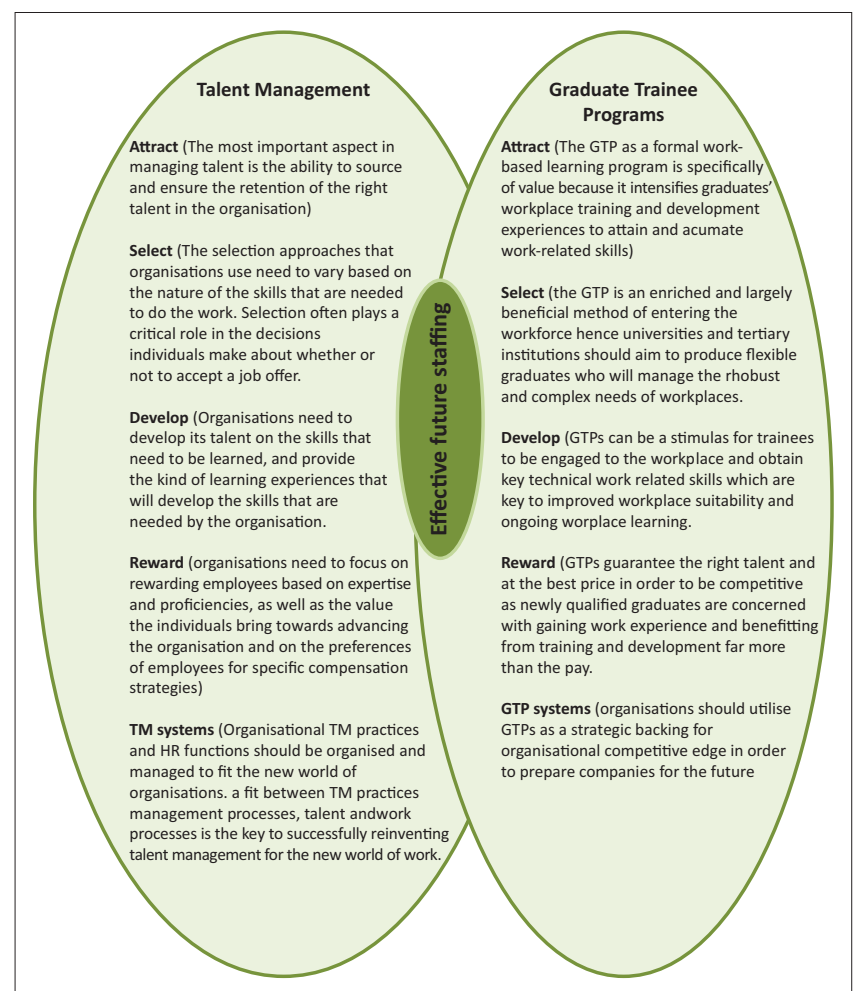

Source: Lawler, E. (2017). Reinventing talent management: Principles and practices for the new world of work. Oakland, CA: Berret-Koehler Publishers, Inc.

FIGURE 1: Tenets that support the link between graduate trainee programmes and talent management. research project because involvement in a research study must always be voluntary.

\section{Participants}

The inclusion criterion was graduate trainees currently undergoing the programme as well as employees who had completed the programme in the last 5 years and were still employed by participating corporates. The graduate trainees were the ideal respondents to participate in the research study because they could furnish the researcher with relevant and current valuable information pertaining to their experiences while undergoing the programme, thus ensuring that the collected data were current, accurate and enriching to the findings of this study. The Slovin Formula was used to compute the sample size to ensure a $95 \%$ level of confidence with a margin error of $5 \%$. In applying the Slovin Formula, the total sample size was calculated at 68 . Respondents were randomly selected and a total of 45 of the 68 questionnaires that were distributed were completed, resulting in a $66 \%$ response rate.

It is noted that (1) $66.7 \%$ of the participants were males and $33.3 \%$ were females; (2) $77.8 \%$ of the participants were in the 25-34 age range and $11 \%$ were between 18 and 24, which meant that they were newly qualified graduates entering the work sector for the first time through the GTPs; (3) $91.1 \%$ of the respondents had undergraduate qualifications, that is a bachelor's degree/advanced diploma/B Tech; and (4) 40.5\% of the respondents had 5 years and above working experience, with $23.8 \%$ of the respondents having between 1 and 2 years' work experience gained through the GTPs (see Table 1).

The summary profile figures highlighted in bold indicate the findings that were an anomaly in a demographic constituent of graduate trainees. Gender imbalances were caused by the fact that participating organisations currently focus their GTPs on engineering and technical skills, which are currently dominated by males in the population that participated; hence $66.7 \%$ of the participants were males while only $33.3 \%$ were females.

Additionally it was an anomaly that a significant percentage $(40.5 \%)$ new hires entering the participating Corporates as graduate trainees had over five years work experience, when

TABLE 1: Demsographic profile of respondents.

\begin{tabular}{lcc}
\hline Dimension & Frequency & Valid Percent \\
\hline Gender & 30 & 66.7 \\
Male & 15 & 33.3 \\
Female & & \\
Age & 5 & 11.1 \\
18-24 & 35 & 77.8 \\
25-34 & 5 & 11.1 \\
35 \& above & & \\
Education & 41 & 91.1 \\
Bachelor Degree/ Advanced Diploma/ B Tech & 4 & 8.9 \\
Honours Degree/ Post Graduate Diploma & & \\
Working Years & 13 & 23.8 \\
1-2 & 15 & 35.7 \\
3-4 & 17 & 40.5 \\
\hline \& above & &
\end{tabular}


in fact the program is tailor made for recent under graduates. the heighted figures reflect the gaps in the administration that the study sought to remedy moving forward.

\section{Data collection tool}

The researcher hand delivered and administered the questionnaire in person to three of the participating corporates and also e-mailed the questionnaire to two participating corporates. The researcher administered the questionnaire through the Human Resources Departments of the population of this study. The questionnaire was centred on the main variables of this study, which were TM and GTPs and the organisational support for graduate trainee programs (OSGTPs). Section A comprised questions pertaining to the demographic information of respondents. Section $B$ entailed questions pertaining to the organisational support for GTPs. Section $C$ aimed to obtain information on the experiences and attitudes of the graduate trainees with the GTPs. Section D aimed to ascertain the views of graduate trainees on the extent to which GTPs contributed to TM. The questionnaire was in English as it was the language most preferred by the respondents.

\section{Data collection procedure}

A request for consent to conduct this study was sent in writing to the Human Resources Managers and Talent Management specialists of the participating corporate organisations as they served as gatekeepers for the corporates because they were responsible for authorising access into the organisations' premises as well as permission for the research to be done (Cresswell, 2013, p. 2012). Once consent was authorised by the 'gatekeepers', the researcher then formally extended an invitation to the respondents to be part of this study.

The respondents were given a 1-week notice of the impending administration of the questionnaire by the researcher and the date and time for administering same was agreed to prior, so that respondents would be prepared. Questionnaires were collected by the researcher after completion or e-mailed in the instance wherein the questionnaire was completed electronically. The questionnaire took between 15 and $20 \mathrm{~min}$ to complete. Respondents were additionally informed that participation was non-mandatory and confidential, and they could withdraw from this study without prejudice. Respondents were further informed that transparency would be maintained throughout the research study as respondents were notified that the results of the research would be primarily used for a master's dissertation.

\section{Data analysis}

Multiple linear regression analysis was conducted with SPSS (version 25), IBM®, Armonk, New York City, to test the hypotheses H1: There is a positive relationship between the GTPs and TM. In addition, a 7-point Likert scale was used to measure the constructs: GTPs and TM, to determine the descriptive results of the two constructs, where the value of 1 correlates to 'strongly disagree' and 7 correlates to 'strongly agree'. The mid-point of the 7-point Likert scale was therefore 3.5. All the mean values less than 3.5 implied that a majority of the respondents tended to disagree with the statement. The values between 3.5 and 4.5 implied that respondents tended to be neutral. All the mean above 4.5 implied that most respondents either agreed or strongly agreed with the statements. Each question per section of the questionnaire was grouped together in the analysis to ensure that comparisons were done. Data were collected over a 2-month period and analysed upon the completion of the data collection process once the data were consolidated. A descriptive analysis of the demographics was done to shed light on the specific cohorts of graduate trainees currently undergoing the GTPs in the population study. The primary and core analysis of the collected data was on the testing of the structural relationships between GTPs and TM.

\section{Ethical consideration}

This article followed all ethical standards for carrying out research without direct contact with human or animal subjects.

\section{Results}

The analysed data shed light on the following themes:

1. Understanding the relationship between GTPs and TM.

2. Attitudes and experiences of graduate trainees.

3. Components of successful graduate traineeship models.

The results further highlighted that there was no significant relationship between GTPs and TM $(p>0.01)$; therefore, $\mathrm{H} 1$ was rejected. The results, however, indicated a strong correlation $(r=0.511)$ between the GTP and TM. The correlation was validated by the results that suggested that a majority of the respondents saw themselves growing within the organisation and this validated the contribution of GTPs to TM (see Table 2).

The null hypotheses could be attributed to the fact that the GTPs were administered parallel to TM primarily because corporates in Eswatini had not identified the value in the link between the two variables as confirmed by this submission from one of the respondents on the questionnaires:

TABLE 2: Regression analysis for hypotheses testing.

\begin{tabular}{|c|c|c|c|c|c|c|}
\hline \multirow[t]{2}{*}{$\overline{\text { Model }}$} & \multicolumn{2}{|c|}{$\begin{array}{l}\text { Unstandardised } \\
\text { coefficients }\end{array}$} & \multirow{2}{*}{$\begin{array}{c}\begin{array}{c}\text { Standardised } \\
\text { coefficients }\end{array} \\
\text { Beta }\end{array}$} & \multirow[t]{2}{*}{$\bar{t}$} & \multirow[t]{2}{*}{ Sig. } & \multirow[t]{2}{*}{$\begin{array}{l}\text { Hypotheses } \\
\text { conclusion }\end{array}$} \\
\hline & $B$ & $\begin{array}{l}\text { Std. } \\
\text { error }\end{array}$ & & & & \\
\hline \multicolumn{7}{|c|}{ Coefficients $\dagger$} \\
\hline GTP & 0.224 & 0.116 & 0.294 & 1.931 & 0.060 & $\begin{array}{l}\text { The results indicate } \\
\text { that there is no } \\
\text { significant relationship } \\
\text { between graduate } \\
\text { trainee programmes } \\
\text { and talent } \\
\text { management ( } p> \\
0.01 \text { ). Therefore, H1 } \\
\text { is rejected. }\end{array}$ \\
\hline
\end{tabular}

GTP, graduate trainee programme.

$\dagger$, Dependent variable: TM. 
'The company's TM needs to be more vibrant and ensure that potentials are aware of the organisations plans about their development for the future.' (Eswatini Electricity Company, talent management specialists)

\section{Attitudes and experiences of graduate trainees}

The central tendency measure of the two constructs, GTPs and TM, was analysed and the overall mean point was 4.5. Withal, an above average mean point suggested that most of the respondents tended to agree or strongly agree with the statements. The results indicated that most of the respondents tended to agree or strongly agree with the statements of GTPs (5.32). However, there was a high standard deviation of 1.02 as some respondents disagreed with the statements of GTPs. The results further indicated that a majority of the respondents tended to agree or strongly agree with the statements of TM (5.54) (see Table 3).

The following statements validate the experiences and attitudes of graduate trainees:

'The GTP is a good way in so far as penetrating the workplace without experience.' (Respondent 25, Eswatini Electricity Company, male, bachelor's degree)

'GTPs are quite useful and beneficial to the new graduate.' (Respondent 28, Eswatini Electricity Company, male, bachelor's degree)

'The GTP is a good tool to unpack tertiary theories.' (Respondent 30, Eswatini Electricity Company, male, bachelor's degree)

However, the researcher identified that there were still areas of improvement in the administration of GTPs identified through the experiences and attitudes of graduate trainees towards the GTPS, and the following statements confirm this:

'Make objectives clear when contracting.' (Respondent 42, Eswatini MTN, female bachelor's degree)

'Colleagues/trainers have no idea of their role in the trainee programme it is not good working while not knowing your future after the programme.' (Respondent 5, Eswatini Railway, male, diploma)

\section{Components of successful graduate traineeship models}

The central tendency measure of the two constructs, GTPs and TM, was analysed using the statements in the questionnaires and the overall mean point was 4.5. The results indicated an above average mean of 5.32 on the graduate trainee's agreeability with the statements on GTPs. This suggested that most of the respondents perceived that their GTPs are well designed. A reviewed GTP from one of the participating corporates included the following

TABLE 3: Central tendency measure of two constructs.

\begin{tabular}{lcc}
\hline Constructs & Mean & Std. deviation \\
\hline GTPs & 5.32 & 1.02 \\
TM & 5.54 & 0.77 \\
\hline
\end{tabular}

GTP, graduate trainee programme; TM, talent management. components: (1) it was conclusive of all functions of the department; (2) monitored the attitudes of the graduate trainees; (3) monitored managerial and leadership potential of the graduate trainees; (4) included periodic assessment of the graduate trainees performance and feedback sessions; (5) the GTPs were documented and formalised to ensure leadership and managerial support, as well; and (6) a collaborative effort in the implementation of the GTP between graduate trainee and mentor was part of the GTP.

\section{Discussion}

This article assessed the relationship between GTPs and TM in corporate organisations in Eswatini that extensively administer the GTPs. Quantitative data collected from 45 graduate trainees currently undergoing the programme, using questionnaires, were used by the researcher to validate the hypothesis that GTPs are significant contributors to TM. This study noted inherent limitations that exist in the administration of GTPs which may hinder the successful implementation of GTPs: (1) there were instances wherein the principles of administering the GTPs are not adhered to, as in some instances individuals who had been part of the work sector were employed as graduate trainees; thus, deserving and eligible newly qualified graduates missed out on this valuable opportunity of being part of the GTP; (2) while the completion rate was quite impressive at $90 \%$, there were instances wherein graduate trainees were impatient to complete the programme and therefore sought alternative permanent employment; (3) the disconnect in administering GTPs to ensure TM, birthed uncertainty in graduate trainees from the perspective of future organisational plans for the graduate trainees; (4) there were instances wherein the actual GTP was discarded and the graduate trainee was by default extended to full-time employment. This is a significant red flag because the graduate trainees are then made to deteriorate as underpaid, expendable sources labour (Maitra \& Maitra, 2015, p. 330). It would be key for Eswatini corporates to address these concerns as they move forward in administering the GTPs.

\section{Conclusion}

It is vital that the administration of GTPs is intentional to ensure that the programme contributes to TM. Corporate organisations should extensively look into their TMPs to ensure that they yield the desired results. Thunnusen et al. (2017, p. 12) contend that research foundations and designs utilised in TM have not been very vigorous and the empirical research that has been conducted on TM has presented a fragmented and onedimensional view on the subject. The administration of GTPs as a WTDP will significantly benefit TM to satisfy future staffing requirements because it will ensure that the GTPs are streamlined in line with all organisation practices aimed at meeting future staffing requirements.

Corporate organisations primarily utilise traditional staffing methods such as interviews, head hunting, labour brokering, poaching and counter-offers for employees who have 
resigned as well as recalling retirees. Therefore, the need for streamlining GTPs as a contributor to TM would undoubtedly have significant value for corporate organisations as it would afford organisations a competitive staffing edge against other corporates that still primarily utilise traditional staffing methods. An integration between the administration of GTPs and TM should be extensively facilitated to ensure that the value of GTPs as a contributor to TM is realised. The integration should be exhaustive of all key components relevant to the successful administration of GTPS, which include sound TMPs, robust leadership and managerial support, establishing key partnerships with universities/ tertiary institutions, to ensure that courses offered meet future organisational skills requirements as well as effective and sufficient financial, training, development, mentorship and coaching initiatives.

\section{Acknowledgements Competing interests}

The authors have declared that no competing interest exists.

\section{Authors' contributions}

All authors contributed equally to this work.

\section{Funding information}

This research received no specific grant from any funding agency in the public, commercial or not-for-profit sectors.

\section{Data availability statement}

Data sharing is not applicable to this article as no new data were created or analysed in this study.

\section{Disclaimer}

The views and opinions expressed in this article are those of the authors and do not necessarily reflect the official policy or position of any affiliated agency of the authors.

\section{References}

Andrews, H., \& Higson, J. (2008). Graduate employability, 'Soft Skills' versus 'Hard' business knowledge: A European study, higher education in Europe. Higher Education in Europe, 33(4), 411-422. https://doi.org/10.1080/03797720802522627

Boudreau, J., \& Ramstad, P. (2007). Beyond HR. The new science of human capital. s.l.: s.n.

Collins, J. (2011). Harvard Business Review's 10 must reads on leadership. s.l.: s.n.

Cresswell, J. (2013). Research design qualitative, quantitative \& mixed method approaches (4th edn.). Croydon: Sage.

De Vos, A., Strydom, H., Fouche, C., \& Delport, C. (2011). Research at grass roots. For the sciences and human service professions (4th edn.). Pretoria: Van Schaik Publishers.

Dirani, K. (2012). Professional training as a strategy for staff development. European Journal of Training and Development, 36(2/3), 158-178. https://doi.org/10.1108/ 03090591211204698

Duplessis, A. 2015. The role of HRM in leadership and development, talent retention knowledge management and employee engagement. Auckland, New Zealand. Published 2015. Business, Retrieved from https://www.semanticscholar.org/ Published 2015. Business, Retrieved from https://www.semanticscholar.org/
paper/The-role-of-HRM-in-leadership-development\%2C-talent-Plessis-Sukumara paper/The-role-of-HRM-in-leadership-development
n/6de4a08bef839e7196357d765ec199dec57060d7

Kotter, J., \& Collins, J. (2011). Harvard Business Review 10 must reads on leadership. s.l.: s.n.

Lawler, E. (2017). Reinventing talent management: Principles and practices for the new world of work. Oakland, CA: Berret-Koehler Publishers, Inc.

Maitra, S., \& Maitra, S. (2015). Tapping into the 'standing-reserve': A comparative analysis of workers' training programmes in Kolkata and Toronto. Studies in Continuing Education, 37(3), 317-332. https://doi.org/10.1080/0158037X.2015.1043988

Mkhonta, M. (2010). General Manager Corporate Services. Eswatini: Eswatini Electricity Company.

Nel, O., Werner, P., Poisat, A., Sono, P., Du Plessis, T., \& Ngalo, A. (2011). Human resources management (8th edn.). s.l.: Oxford University Press.

Robins, S., \& Judge, T. (2008). Organisational behaviour (15th edn.). s.l.: s.n.

Saunders, M., Lewis, P., \& Thornhill, A. (2016). Research methods for business studies (7th edn.). London: Pearson Education Limited.

Thunnussen, M., \& Gallardo-Gallardo, E. (2017). Talent management in practice. An integrated and dynamic approach. Retrieved from http://0.searchebscohost.com. tkplib01.tut.ac.za

Waheed, A., \& Zaim, A.H. (2015). A model for talent management and career planning. Educational Sciences: Theory and Practice, 15(5), 1205-1213. 